\title{
Comparison of photosynthesis activities among ten species of Salvia L.
}

\author{
Khalid Faiq Darweesh \\ University of Garmian College of Education \\ Khalid.palani@garmian.edu.krd
}

\begin{abstract}
The study included survey to record ten species of Salvia L. (Lamiaceae) at spring session in three physical district of Iraqi vegetation within Kurdistan region.After identified species of studied genus the study included field investigation of some photosynthetic parameters by PP system TPS-2.the result showed different pattern of these species in compared with the elasticity of geographic distribution especially in Compensation point of $\mathrm{CO}_{2}$ and the leaf contents of photosynthetic pigments.
\end{abstract}

\section{Introduction}

Salvia L. one of widest in Lamiaceae Lidl family including 1000 species compared with other member of genus Lamiaceae 3500 species of 250 genus (kintzios, 2000 and simpson). Al-Hussaini (2006 )record 30 species more of them in north of Iraq. These genus show defenses growth forms and secondary metabolites (walker and sytama ,2007 )in addition to differences in ecological relationship (Panagiotopolus etal., 2000)

It has been that some aspect this genus not been studied speeially physislogical aspect in addition to it is elasticity and have no interest by researcher ( Alziar 1989 and Shirsat etal. 2012) Generally saliva are c3 plant in photosynthesis pathway (Waston and Dollwitz ,1992 )this study aim to record some parameter of it is physislogical aspect for salvia species grow in their physical district in northern Iraq .

\section{Material and methods}

\section{Identification of species:}

The studied species achieved according to (Harly etal. 2004 and Al-Hussaini, 2006) and supported by Iraq National Herbarium - Baghdad. 


\section{Determination of some physiological parameter related to Photosynthesis:}

Different physiological parameter referred below estimated by PPphotosynthesis system TBS-2, according to it is supplied guide of operation within different levels of atmospheric $\mathrm{CO}_{2}$ :

- Reference $\mathrm{CO}_{2}$ concentration (ppm).

- Differential $\mathrm{CO}_{2}$ concentration (ppm).

- PAR(Photosynthetically active radiation) $\left(\mu \mathrm{mol} \mathrm{m} \mathrm{m}^{-2} \mathrm{~s}^{-1}\right)$.

- $\mathrm{GC}\left(\mathrm{mmol} \mathrm{m} \mathrm{s}^{-2} \mathrm{~s}^{-1}\right)$ Calculated Stomal Conductance.

- Evap (Evaporation) (mmol m $\left.\mathrm{m}^{-2} \mathrm{~s}^{-1}\right)$.

- $\left(\mu \mathrm{mol} \mathrm{m} \mathrm{m}^{-2}\right)$ (Calculated assimulative rate) PN.

- $\mathrm{Ci}(\mathrm{PPm})\left(\right.$ Calculated sub-stomal $\mathrm{CO}_{2}$ concentration.

\section{Result and Discussion:}

The field survey record ten species of Salvia L.( (S. bracteata, $S$. compressa , S. indica , S. multicaulis , S. palaestina , S. sclerea, $S$. sclereopsis , S. spinosa , S. syriaca g. viridis ) in studied area which identified in field by available references then supported by Iraqi Natural Herbarium - Baghdad, and followed by field measuring of some physiological parameters especially (GC) Calculated Stomatal Conductance, Transpiration , Respiration and Photosynthesis Net. Using the open systems of PPsystemTS-2 to controlling input and output $\mathrm{CO}_{2}$ (Atmospheric $\mathrm{CO}_{2}$ and Humidity) and calculation the (Differential $\mathrm{CO}_{2}$ concentration), (PAR) Photosynthetically Active Radiation ,(PN) Net Photosynthetic Rate ,(GC) Calculated Stomal Conductance, Evaporation (Evap) and Calculated sub stomatal concentration $(\mathrm{Ci})$ by controlling

The results in figure (1-10) showed that Compensation point of $\mathrm{CO}_{2}$ (input $\mathrm{CO}_{2}$ equal to output $\mathrm{CO}_{2}$ ) in other form the plant assimilate only the respiration yielding $\mathrm{CO}_{2}$ (Strzalka and Pieter,1999) and Photosynthesis Net is Zero, because the assimilated $\mathrm{CO}_{2}$ ingoing from metabolism(destroy by respiration).

The resut noted that S. indica and S. palaestina have Compensation point of $\mathrm{CO}_{2}$ near to atmospheric $\mathrm{CO}_{2}(360-380 \mathrm{ppm})$ which refer to high retio of respiration in these species which supported by large stom of S. indica and high level of stomatal frequency of S. palaestina(figure 11,12). 
The decreasing in $\mathrm{CO}_{2}$ followed by decreasing of photosynthesis activity until reach it is point of compensation which was 290 of S. spinosa and 280ppm of S sclarea and S. multicaulis, also decreasing in photosynthesis activity followed with decreasing in respiration when assimilation continuous in this low point as in $S$. compressa, $S$. syriaca, and $S$. viridis which arrived less than $200 \mathrm{ppm}$. For that these species have ability assimilation in low concentration of $\mathrm{CO}_{2}$ which is normal phenomenon in $\mathrm{C} 4$ plant (Sage and Monson. 1999), also according to this point the species as ( S. multicaulis ,S. sclarea and S. spinosa )have characters of C3-C4 intermediate plants in it is photosynthetic pathway, while other studied species regarded as C3 plants ,this parameter may be useful to classify these large number of species of Salvia in the world in to three categories of photosynthetic pathway.

Other characters such as stomatal conducting was related to leaves anatomy of studied species especially stomata also environmental factors soil and weather may have it is effect (Kapotis etal., 2003 and Miyashita ،2005) in addition to other sources of differences such as elevation and annual changing in precipitation.

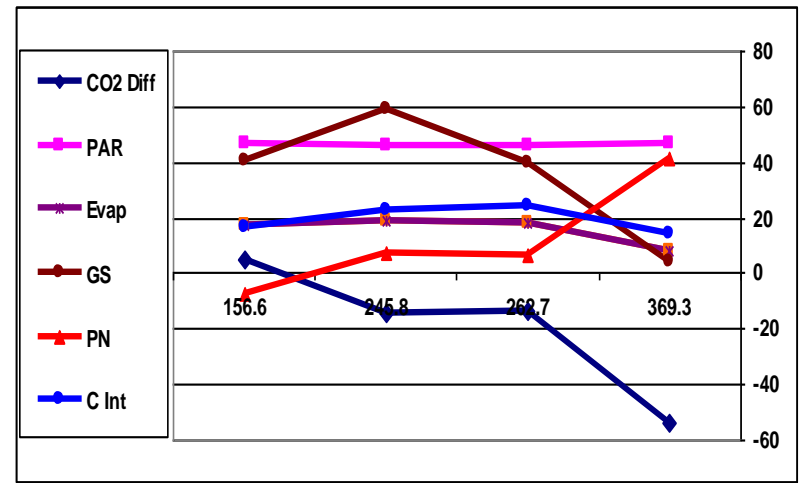

Figure (1) Physiological changes within different concentration of atmospheric $\mathrm{CO} 2$ for $\mathrm{S}$.

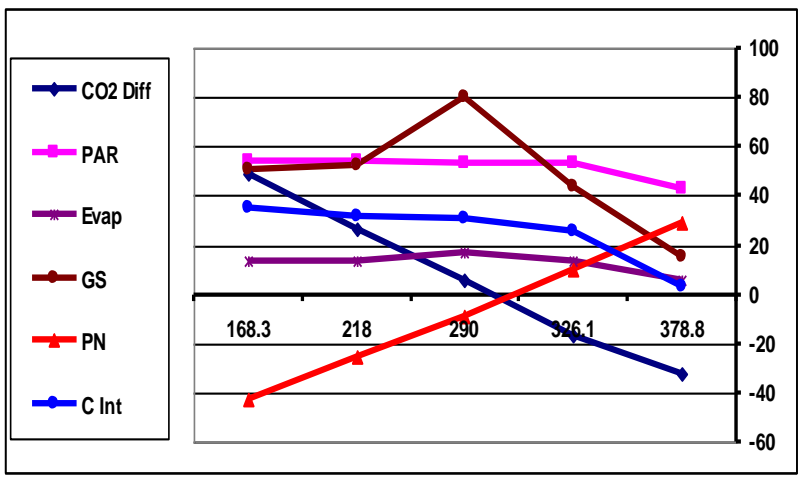

Figure (3) Physiological changes within different concentration of climate $\mathrm{CO}_{2}$ for $S$. multicaulis

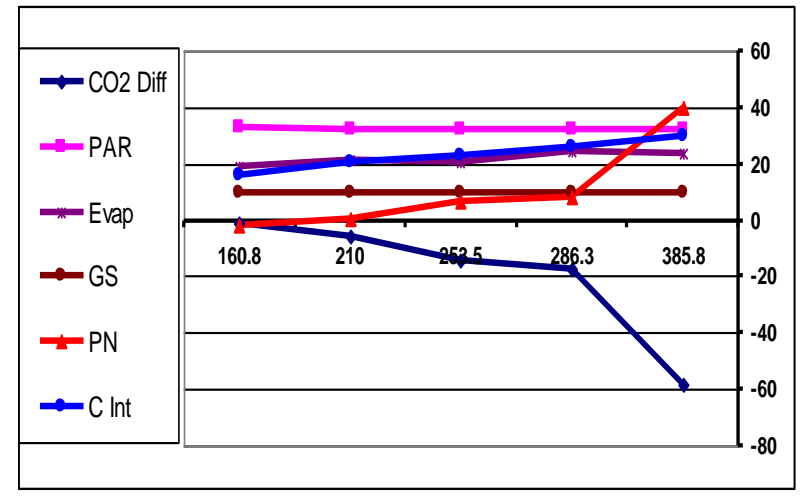

Figure (2) Physiological changes within different concentration of atmospheric $\mathrm{CO} 2$ for $S$. bracteata

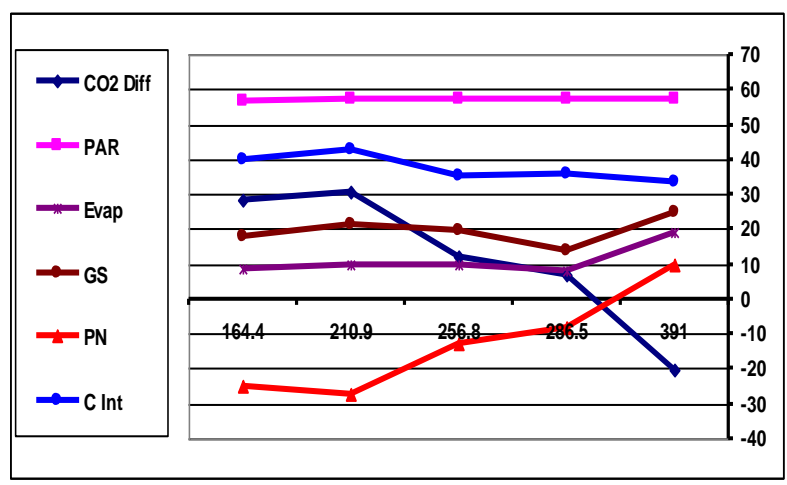

Figure (4) Physiological changes within different concentration of atmospheric $\mathrm{CO} 2$ for $S$. indica 


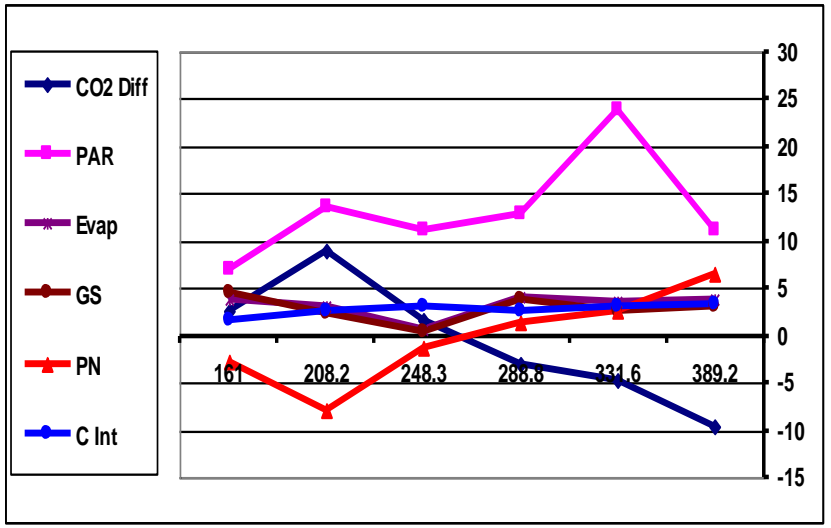

Figure (5) Physiological changes within different concentration of atmospheric $\mathrm{Co} 2$ for $S$. sclarea

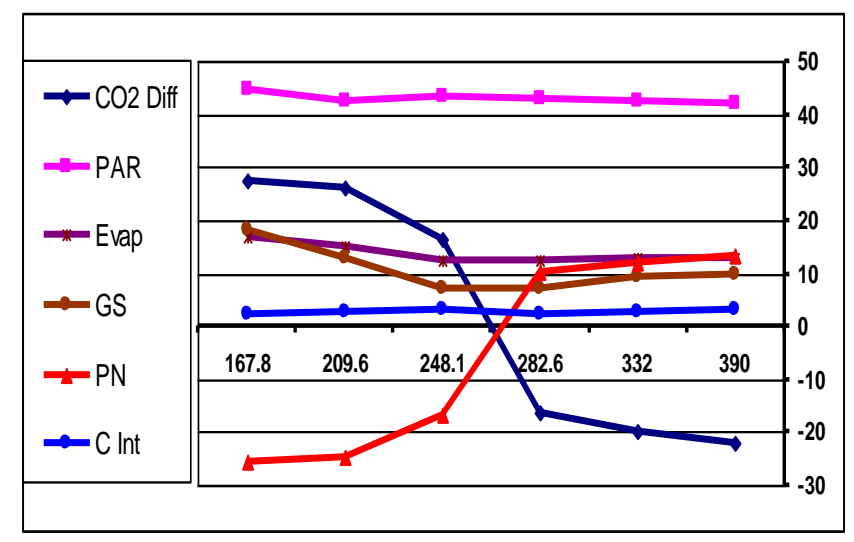

Figure (7) Physiological changes within different concentration of atmospheric $\mathrm{Co} 2$ for $S$. spinosa

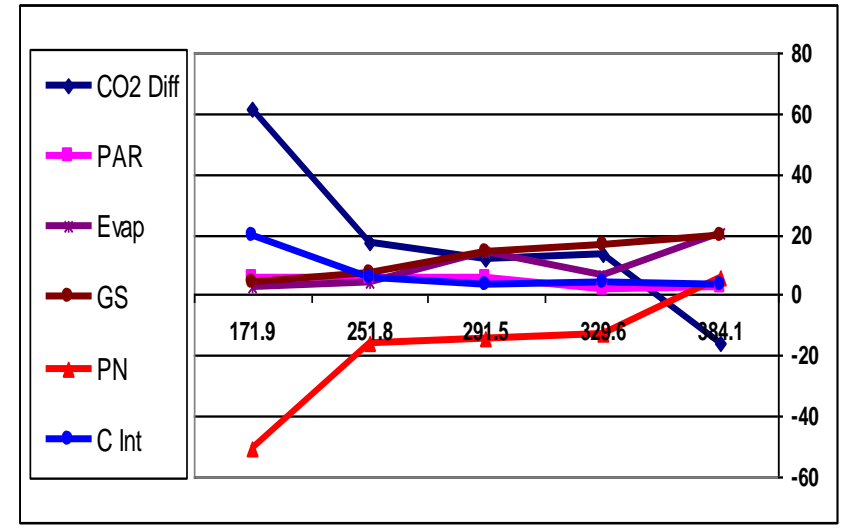

Figure (6) Physiological changes within different concentration of atmospheric Co2 for $S$. palaestina

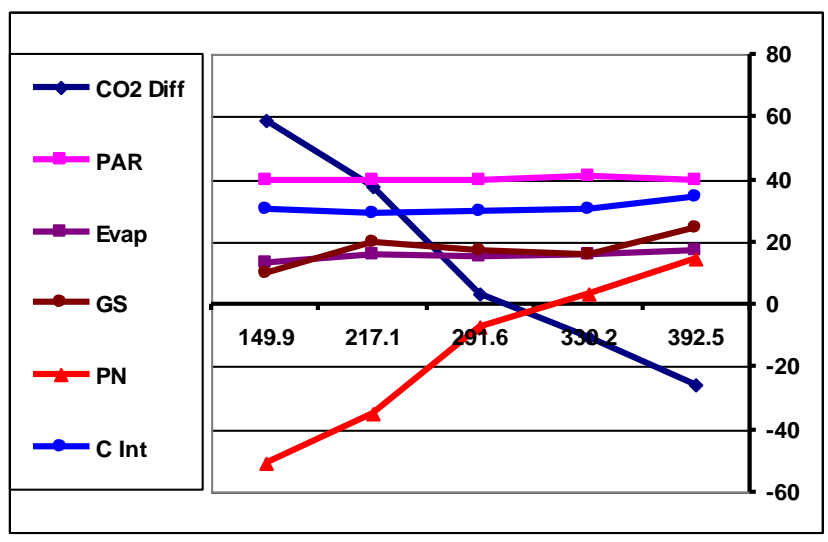

Figure (8) Physiological changes within different concentration of atmospheric $\mathrm{Co} 2$ for $S$. sclareopsis

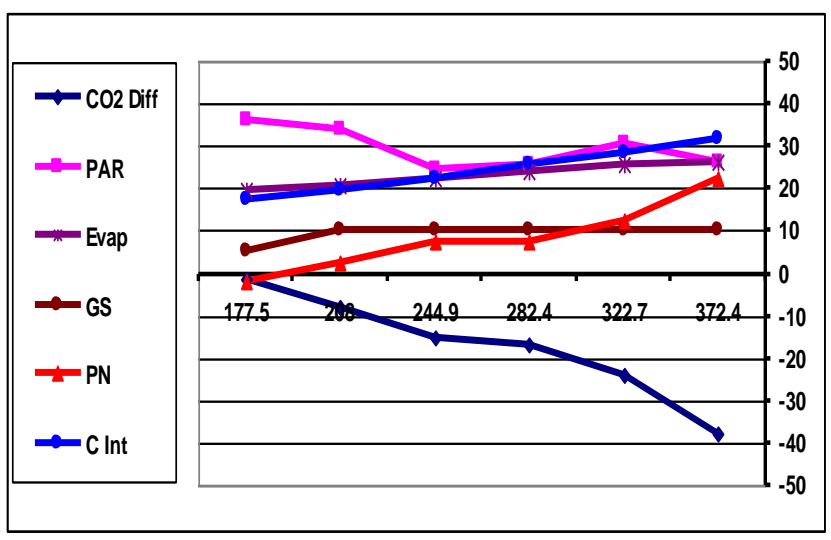

Figure (10) Physiological changes within different concentration of atmospheric $\mathrm{Co} 2$ for $S$. syriaca concentration of atmospheric $\mathrm{Co} 2$ for $S$. viridis 

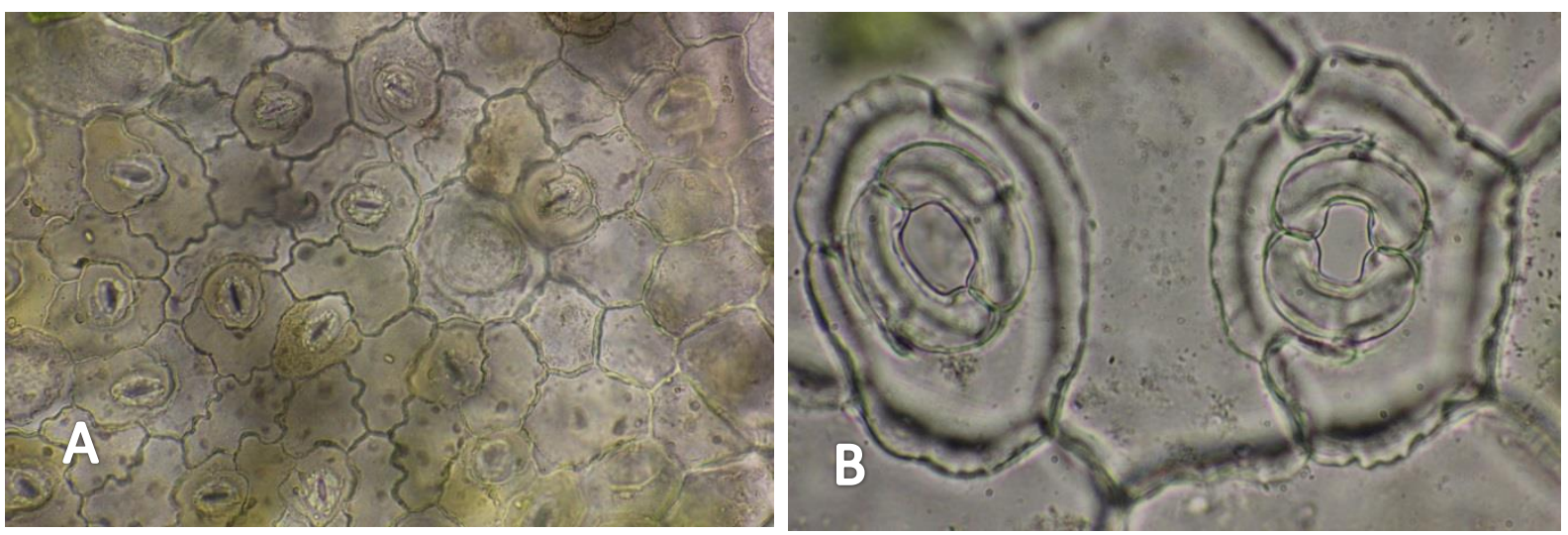

'Figure 11: Epidermis showed stomatal frequency of S. palaestina (A), opening stoma in S. indica (B)

\section{References:}

- Al-Hussaini ,Aseel Fuad A. (2006). Comparative Morphological Study for more than thirty species of Salvia L. (Labiatae) in Iraq. University of Baghdad .Master thesis.

-Alziar, G.(1989) Catalogue synonymique des Salvia du monde (Lamiaceae). Muséum d'histoire naturelle. French.

-Harley, R.M., Atkins, S., Budantsev, A.L., Cantino, P.D., Conn, B.J., Grayer, R., Harley, M.M., De Kok, R., Krestovskaja, T., Morales, R., Paton, A., Ryding, O., and Upson, T. (2004). Labiatae. In: Kadereit JW, ed. The families and genera of vascular plants, Vol. VII. - flowering plants: dicotyledons (Lamiales except Acanthaceae including Avicenniaceae). Berlin and Heidelberg: Springer Verlag. 167-275.

-Kintzios, S.E. (2000). SAGE the Genus Salvia. Harwood Academic Publishers. Netherlands. Pp:289.

-Panagiotopoulos, E. , C. Kapetanos , M. Skapeti , C. Cholevas , J. Drossopoulos , M. Loukas and S. E. Kintzios (2000). The ecophysiology of Salvia: Disorders and Adaptation. from ( Sage The Genus Salvia) Harwood Academic Publishers, The Netherlands, pp:27-46. 
-Shirsat, R., Kokate, P., and Surdakar. (2012) Morphological and Anatomical Characterization of Salvia Plebeia from Maharashtra (India). Bioscience Discovery. 3(2): 165-168.

-Simpson, M.G. (2006). Plant Systematic. Elsevier Academic Press.Canada.

-Walker, J.B., Sytsma, K.J. (2007). Staminal evolution in the genus Salvia (Lamiaceae): molecular phylogenetic evidence for multiple origins of the staminal lever. Annals of Botany. 100: 375-391.

-Watson, L., and Dallwitz, M.J. (1992). The families of flowering plants: descriptions, illustrations, identification, and information retrieval. Version: 19th December 2012. http://delta-intkey.com.

-Kapotis G., Zervoudakis G., Veltsistas T. and Salahas G.(2003) Comparison of Chlorophyll Meter Readings with Leaf Chlorophyll Concentration in Amaranthus vlitus: Correlation with Physiological Processe. Russian Journal of Plant Physiology.50 (3) pp. 395-397.

-Miyashita, K. .(2005) Recovery responses of photosynthesis, transpiration, and stomatal conductance in kidney bean following drought stress. Environmental and Experimental Botany, Volume 53, Issue 2, Pages 205214. Okayama, Japan

-Sage , R. F., \& Monson, R. K. (1999) C4 Plant Biology. Academic Press.U.K.

-Strzalka ,K and Pieter K.(1999)Plant Physiology Ecology. Academic press. USA. 